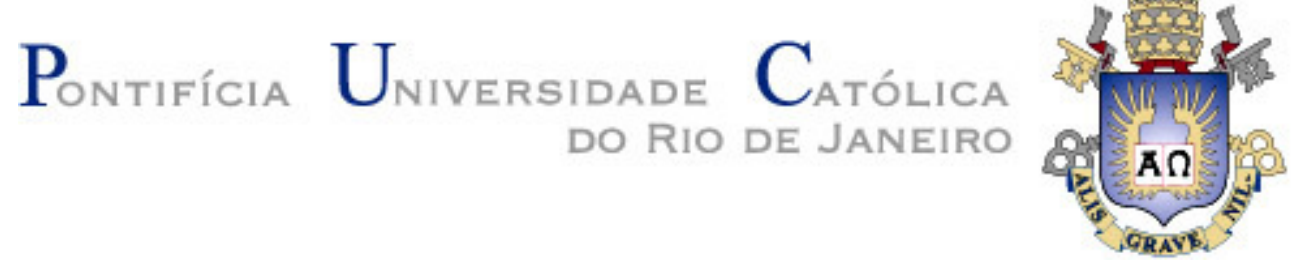

Anna Maria Calvão Gobbo

Liderança Autêntica e Desempenho:

Uma Análise Tridimensional

Dissertação de Mestrado

Dissertação apresentada ao Programa de Pósgraduação em Administração de Empresas da PUCRio como requisito parcial para obtenção do título de Mestre em Administração de Empresas.

Orientadora: Prof ${ }^{a}$. Flávia de Souza Costa Neves Cavazotte

Rio de Janeiro

Abril de 2013 


\section{Anna Maria Calvão Gobbo}

\section{Liderança Autêntica e Desempenho: Uma Análise \\ Tridimensional}

Dissertação apresentada como requisito parcial para obtenção do grau de Mestre pelo Programa de PósGraduação em Administração de Empresas da PUC-Rio. Aprovada pela Comissão Examinadora abaixo assinada.

\section{Profa. Flávia de Souza Costa Neves Cavazotte \\ Orientadora Departamento de Administração - PUC-Rio}

Prof. Jorge Manoel Teixeira Carneiro Departamento de Administração - PUC-Rio

Prof. Valter de Assis Moreno Jr UERJ

Profa. Mônica Herz Vice-Decana de Pós-Graduação do CCS - PUC-Rio 
Todos os direitos reservados. É proibida a reprodução total ou parcial do trabalho sem autorização da universidade, da autora e da orientadora.

\section{Anna Maria Calvão Gobbo}

Graduou-se em Administração de Empresas na Pontifícia Universidade Católica do Rio de Janeiro em 2008. Cursou Pós-Graduação Lato Sensu em Recursos Humanos na Fundação Coppead - UFRJ em 2009. Pesquisadora das áreas de Liderança e Comportamento Organizacional.

Ficha Catalográfica

Gobbo, Anna Maria Calvão

Liderança Autêntica e Desempenho: Uma Análise Tridimensional / Anna Maria Calvão Gobbo; orientadora: Flávia de Souza Costa Neves Cavazotte. - Rio de Janeiro : PUC, Departamento de Administração, 2013.

111 f.: il. ;

Dissertação (mestrado) - Pontifícia Universidade Católica do Rio de Janeiro, Departamento de Administração.

Incluí referências bibliográficas.

1. Administração - Teses. 2. Liderança. 3. Capital Psicológico. 4. Desempenho. I. Cavazotte, Flávia de Souza Costa Neves. II. Pontifícia Universidade Católica do Rio de Janeiro. Departamento de Administração. III. Título. 
Aos meus pais, com amor incondicional 


\section{Agradecimentos}

A Deus em primeiro lugar, que me trouxe até aqui, minha grande fortaleza e abrigo. Obrigada por fechar as portas certas, transformando dificuldades em oportunidades; pelos anjos que eu encontrei no caminho, pela mão estendida e pela força para me manter firme.

Aos meus pais, por sempre enxergarem o melhor em mim. Vocês foram meus olhos quando eu não pude ver, alimentaram minha fé quando me vi perdida, me deram raízes, asas e principalmente amor.

À Professora Doutora Flávia Cavazotte, por todo o apoio, conselhos, conversas e serenidade. Obrigada não só pelo auxílio acadêmico mas por todo o carinho e inspiração. Foi um prazer enorme trabalhar com você.

Aos meus queridos amigos que participaram ativamente dessa etapa,obrigada pela força, disponibilidade e companheirismo. Vocês tornaram tudo mais leve, sempre presentes, me emprestaram ombros, abraços e ouvidos. Aos amigos "novos" Thais, João, Manu, Malu, Rebeca e Fernando - um obrigada ainda mais especial... Preocupações compartilhadas, risadas multiplicadas, esforço somado e olha onde nós chegamos!

Aos professores da PUC-Rio que contribuíram para minha formação, desde a Graduação até o Mestrado. Agradeço especialmente àqueles que despertaram e reforçaram meu interesse pela Academia: à querida Professora Maria Cristina Carneiro, seu incentivo e apoio foram fundamentais no início desta jornada; e ao Professor Doutor Jorge Brantes, pelo conhecimento compartilhado e oportunidade em fazer parte do seu grupo de pesquisa.

À FAPERJ e CNPq pelos recursos concedidos, à Pontifícia Universidade Católica do Rio de Janeiro pelo ambiente e infra-estrutura - aspectos fundamentais à realização deste trabalho.

Agradeço ainda aos funcionários da empresa objeto deste estudo que viabilizaram a realização da pesquisa: ao Guilherme Gonçalinho por todo o apoio, interesse e profissionalismo, aos Operadores e Superintendentes pelo empenho e participação ativa, e especialmente ao Sr. Luiz Renato pela generosidade e pelo voto de confiança.

Obrigada a todos que participaram de forma direta ou indireta dessa caminhada, sem vocês eu não teria chegado até aqui! 


\section{Resumo}

Gobbo, Anna Maria Calvão; Cavazotte, Flávia de Souza Costa Neves. Liderança Autêntica e Desempenho: Uma Análise Tridimensional. Rio de Janeiro, 2013. 111p. Dissertação de Mestrado - Departamento de Administração, Pontifícia Universidade Católica do Rio de Janeiro.

Este estudo analisou a influência exercida pela liderança autêntica sobre o desempenho dos trabalhadores, investigando os mecanismos psicológicos que explicariam esta conexão. O estudo se baseou em uma amostra de 315 trabalhadores do segmento de distribuição de petróleo e derivados. Os resultados sugerem uma relação direta entre liderança autêntica e os três tipos de desempenho pesquisados - no contexto (cidadania organizacional), na tarefa e em segurança; além de uma contribuição positiva ao desenvolvimento do capital psicológico dos subordinados.Relações positivas entre o capital psicológico individual e desempenho também foram encontradas. Foi observado ainda que o capital psicológico do indivíduo parece ser uma via relevante através da qual líderes mais autênticos promoveriam o comportamento de segurança entre seus subordinados.

\section{Palavras-chave}

Liderança autêntica; capital psicológico; desempenho na tarefa; desempenho no contexto; desempenho em segurança. 


\section{Abstract}

Gobbo, Anna Maria Calvão; Cavazotte, Flávia de Souza Costa Neves (Advisor). Authentic Leadership and Performance: A ThreeDimensional Analysis. Rio de Janeiro, 2013. 111p. MSc. Dissertation Dissertação de Mestrado - Departamento de Administração, Pontifícia Universidade Católica do Rio de Janeiro.

The present study analyzed the influence of authentic leadership on follower individual performance, investigating the psychological mechanisms that could explain this relation. The study was based on a sample of 315 individuals working in the field of oil distribution. Results indicated a direct relationship between authentic leadership and three types of individual performance - task performance, contextual performance and safety performance; besides a positive contribution in the development of subordinate's psychological capital. Positive relations between individual psychological capital and performance were also found. It was also noticed that follower's psychological capital seems to be a relevant path through which authentic leaders promote safety behaviors.

\section{Keywords}

Authentic leadership; psychological capital; contextual performance; task performance; work safety. 


\section{Sumário}

1. INTRODUÇÃO 13

$\begin{array}{ll}\text { 1.1. Problema de Pesquisa } & 15\end{array}$

$\begin{array}{ll}\text { 1.2. Objetivos } & 17\end{array}$

$\begin{array}{ll}\text { 1.3. Relevância do Estudo } & 17\end{array}$

1.4. Delimitação do Estudo 19

1.5. Estrutura do Trabalho 19

2. REFERENCIAL TEÓRICO 21

2.1. Liderança Autêntica 21

2.1.1. Autenticidade 22

2.1.2. Definição de Liderança Autêntica 24

2.1.3. Diferenciando Liderança Autêntica de Outras Teorias 28

2.1.4. Liderança Autêntica em Contextos Extremos 31

2.1.5. Liderança Autêntica e Resultados no Trabalho 32

2.2. Capital Psicológico 35

2.2.1. Origens do conceito 35

2.2.2. Definição de Capital Psicológico 36

2.2.3. Componentes do Capital Psicológico 39

2.2.4. Capital Psicológico e Liderança Autêntica 41

2.2.5. Capital Psicológico e Resultados no Trabalho 44

2.3. Desempenho no Trabalho 45

2.3.1. Desempenho no Contexto 48

2.3.1.1. Comportamentos de Cidadania Organizacional 49

2.3.1.2. Capital Psicológico e Comportamentos de Cidadania Organizacional 51

2.3.2. Desempenho na Tarefa 53

2.3.2.1. Capital Psicológico e Desempenho na Tarefa 53

2.3.3. Desempenho em Segurança 54

2.3.3.1. Capital Psicológico e Desempenho em Segurança 56 
4. METODOLOGIA 60

4.1. Tipo de pesquisa 60

4.2. Universo e Amostra 60

4.3. Coleta de dados 62

4.3.1. Primeira Fase 63

4.3.2. Segunda Fase 66

4.3.3. Terceira Fase $\quad 67$

4.4. Tratamento dos dados 68

4.5. Limitações do método 68

5. ANÁLISE DOS DADOS 70

5.1. Discussão dos Resultados 78

5.2. Proposição de Modelos Alternativos 80

6. CONCLUSÕES E RECOMENDAÇÕES 83

6.1. Conclusões e Implicações 83

6.2. Implicações Gerenciais 85

6.3. Limitações e Sugestões para Pesquisas Futuras 81

7. REFERÊNCIAS BIBLIOGRÁFICAS 88

8. APÊNDICE 97

8.1. Apêndice A 97

8.2. Apêndice $B \quad 104$

8.3. Apêndice $C \quad 108$ 


\section{Lista de figuras}

Figura 1: Modelo da Pesquisa 58

Figura 2: Terminais de Distribuição 61

Figura 3: Pacote de pesquisa 1‥ fase 63

Figura 4: Resultados obtidos para o modelo proposto ${ }^{\mathrm{a}} \quad 77$

Figura 5: Modelo Adaptado ${ }^{a} 01$ Liderança Autêntica $\rightarrow$ Desempenho $\quad 81$

Figura 6: Modelo adaptado 02 Liderança Autêntica $\rightarrow$ Capital

Psicológico $\rightarrow$ Segurança $\quad 82$ 


\section{Lista de tabelas}

Tabela 1: Comparativo Liderança Autêntica, Transformacional e Ética 29

Tabela 2: Médias, Desvios-Padrão, Correlações e Alfa de Cronbach 70

Tabela 3: Regressão Múltipla para Capital Psicológico:

Liderança e Personalidade

71

Tabela 4: Regressão Hierárquica para OCB: Liderança Autêntica

e Capital Psicológico

72

Tabela 5: Regressão Hierárquica para Desempenho na Tarefa:

Liderança Autêntica e Capital Psicológico

Tabela 6: Regressão Hierárquica para Desempenho em

Segurança: Liderança Autêntica e Capital Psicológico

77

Tabela 7: Regressões para Desempenho no Contexto, na Tarefa

e em Segurança: Liderança Autêntica

80

Tabela 8: Regressão hierárquica para Desempenho em

Segurança: Modelo Completo

82 
Orei, e foi-me dada a prudência; supliquei e veio a mim o espírito da sabedoria. Preferi a Sabedoria aos cetros e tronos e em comparação com ela, julguei sem valor a riqueza; a ela não igualei nenhuma pedra preciosa, pois, a seu lado, todo o ouro do mundo é um punhado de areia e diante dela, a prata, será como a lama. Amei-a mais que a saúde e a beleza, e quis possuí-la mais que a luz, pois o esplendor que dela irradia não se apaga. Todos os bens me vieram com ela, pois uma riqueza incalculável está em suas mãos.

Bíblia Sagrada, Livro da Sabedoria (Sb 7, 7-11) 